\title{
Ascorbic acid in fetal human brain
}

\author{
B. P. F. ADLARD, S. W. DE SOUZA, and SUSAN MOON \\ From the Department of Child Health, University of Manchester
}

\begin{abstract}
Adlard, B. P. F., De Souza, S. W., and Moon, S. (1974). Archives of Disease in Childhood, 49, 278. Ascorbic acid in fetal human brain. Ascorbic acid concentrations in fetal human forebrain in the period 11 to 19 weeks' gestational age were 4 to 11 times higher than those of adults. Levels fell progressively with increasing gestational age but, in term babies dying within 4 weeks of birth, were still at least 3 times those of adults. It was confirmed that, in women delivering at term, ascorbic acid concentrations are approximately 4 times higher in cord blood plasma than in maternal blood plasma. The possible importance of ascorbic acid for normal human brain development is discussed.
\end{abstract}

The adult brain of several mammals including man has a high concentration of ascorbic acid when compared with most other organs (Yavorsky, Almaden, and King, 1934). In the brain of the immature rat, a species which synthesizes ascorbic acid, levels are even higher than those of adult brain and fall progressively during the major period of brain growth (Allison and Stewart, 1973; Adlard, De Souza, and Moon, 1973). To determine whether a similar phenomenon occurs in man, ascorbic acid concentrations have been examined in developing human brain.

Early reports suggested a marked fetal/maternal plasma gradient for ascorbic acid at term (Teel, Burke, and Draper, 1938; Snelling and Jackson, 1939). We have confirmed this finding and have attempted to investigate the possibility that such a gradient might result solely from changes in maternal levels during labour. For comparison, plasma ascorbic acid has been examined in groups of women at different stages of pregnancy and in women who were not pregnant.

\section{Methods}

Gestational age was calculated from the first day of the last menstrual period. Brains were obtained from three sources. Group 1, induced abortions, 11 to 19 weeks' gestational age (no. $=16)$; group 2, 10 perinatal deaths and one 3-month-old baby; group 3, adults (17-83 years), dying in hospital of non-neurological disease (no. = 6). Post mortem loss of brain ascorbic acid under normal refrigerated conditions was found to be negligible when up to 96 hours elapsed between death and

Received 12 September 1973. availability of the specimen. Most brains were obtained well within this time.

Changes in fetal tissue levels might reflect differences in maternal intake of vitamin $\mathrm{C}$, which was not assessed. However, mothers of babies dying in the perinatal period (group 2) were not prescribed ascorbic acid during pregnancy. It seems unlikely that women contemplating termination of pregnancy (group 1) would take extra amounts of vitamin C. Finally, the hospital diet which the adults (group 3 ) received was considered to contain an adequate amount of vitamin $\mathrm{C}$.

Ascorbic acid was determined in whole forebrain in group 1, in a representative slice of frontal cortex (including underlying white matter) in group 3 , and by either of these procedures in group 2 . In groups 2 and 3 ascorbic acid was also estimated in portions of brainstem (medulla) and cerebellum. Results using the dinitrophenylhydrazine procedure (Roe and Kuether, 1943) are presented. The method has been widely used in animal tissues and seems to be highly specific for ascorbic acid in brain since chromogenic material almost disappears from guinea-pig brain when they are fed a diet free of vitamin C (Hughes, Hurley, and Jones, 1971), and a specific gas liquid chromatographic method gives almost identical results when applied to both adult and immature rat brain (Allison and Stewart, 1973). Nevertheless, some human forebrain samples were also analysed by the dichlorophenolindophenol procedure (Evelyn, Malloy, and Rosen, 1938). Despite the different assay principles involved, this method gave results very similar to those obtained by the Roe and Kuether procedure.

Water content was determined by drying to constant weight and protein by the method of Lowry et al. (1951).

Blood was collected from 13 healthy nonpregnant women not taking contraceptive steroids and from 33 women at different stages of pregnancy. In a further 16 women, delivering at term (38-42 weeks) after an uncomplicated pregnancy, blood was collected at the 
onset of labour (induced by membrane rupture or oxytocin infusion), when labour was well established (4-6 hours), and from the umbilical vein immediately after delivery of the placenta.

Blood was collected in heparinized tubes and centrifuged within one hour, after which plasma and cells were separated and stored at $-20^{\circ} \mathrm{C}$ for up to 2 weeks before assay. Such a procedure does not lead to deterioration of ascorbic acid (Baker and Frank, 1968), which was determined by the method of Roe and Kuether (1943). Plasma urea was determined according to Fawcett and Scott (1960).

\section{Results}

Fetal forebrain ascorbic acid concentrations were very high and fell substantially with age (Fig.). In

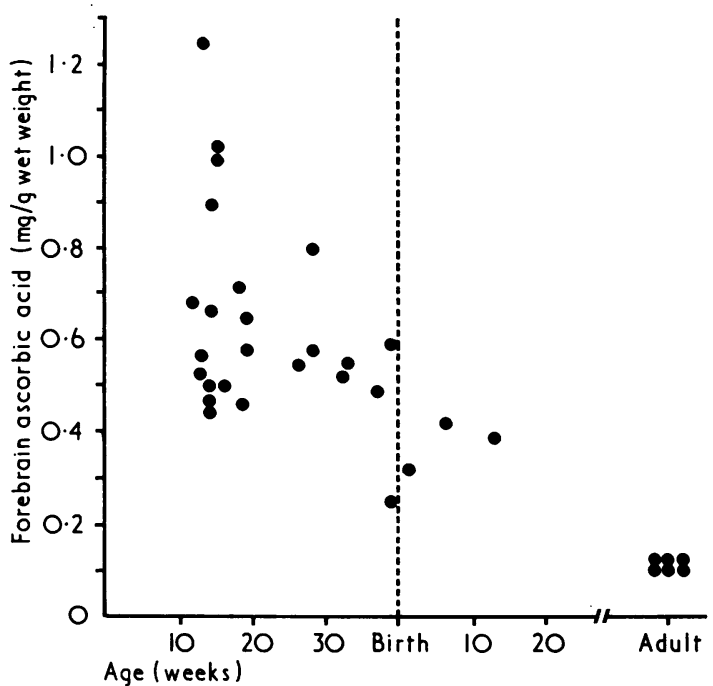

FIG.-Ascorbic acid concentrations in human forebrain samples at different ages.

the period from 11 to 19 weeks' gestational age, levels varied between 4 and 11 times the mature values. 7 fetal brains from this age group, having a mean ascorbic acid level of $0.85 \mathrm{mg} / \mathrm{g}$ (range 0.45-1 25), showed a mean water content of $909 \cdot 1$ $\mathrm{mg} / \mathrm{g}$ and protein concentration of $50.4 \mathrm{mg} / \mathrm{g}$. Thus the mean concentration of nonprotein solids was $40.5 \mathrm{mg} / \mathrm{g}$ (range 33.4-60.2) of which ascorbic acid formed the remarkably high proportion of $2 \cdot 1 \%$ (range $1 \cdot 1-3 \cdot 4$ ).

In a number of near-term babies (37-42 weeks' gestational age) who died within 4 weeks of birth (conceptual age at death 37-46 weeks) forebrain ascorbic acid levels remained high, at least 3 times those of adults (Table I). The difference was also
TABLE I

Ascorbic acid concentrations in perinatal and adult brain

\begin{tabular}{l|c|c|c}
\hline & Forebrain & Cerebellum & Brainstem \\
\hline Perinatal desths (37-46 & 0.414 & 0.385 & 0.201 \\
wk conceptual age) & $\pm 0.136(5)$ & $\pm 0.083(6)$ & $\pm 0.040(5)$ \\
Adults (17-83 yr) & 0.127 & 0.209 & 0.153 \\
& $\pm 0.018(6)$ & $\pm 0.041(6)$ & $\pm 0.029(6)$ \\
P & $<0.001$ & $<0.001$ & $<0.05$ \\
Ratio & 3.25 & 1.84 & 1.31 \\
& & & \\
\hline
\end{tabular}

Note: Each value (mg ascorbic acid/g wet weight) is the mean $\pm \mathrm{SD}$ of the number of brains indicated in parentheses. Differences between perinatal and adult values were compared using Student's ' $t$ ' test.

detectable in the cerebellum, though less conspicuous, but was only barely significant in brainstem. When a comparison is made with fetal plasma (Table II) it seems that the brain/plasma

TABLE II

Ascorbic acid and urea concentrations in maternal and cord blood at term

\begin{tabular}{l|c|c|c}
\hline & \multicolumn{2}{|c|}{$\begin{array}{c}\text { Ascorbic acid } \\
(\mathrm{mg} / 100 \mathrm{ml})\end{array}$} & $\begin{array}{c}\text { Urea } \\
(\mathrm{mg} / 100 \mathrm{ml})\end{array}$ \\
\cline { 2 - 3 } & Plasma & Cells & Plasma \\
\hline Maternal blood & 0.45 & 0.36 & 20.8 \\
$\quad$ (onset of labour) & $\pm 0.27^{\star}$ & $\pm 0.15^{\star}$ & \pm 5.0 \\
Maternal blood & 0.47 & 0.33 & 19.3 \\
(labour established) & $\pm 0.38^{\star}$ & $\pm 0.14^{\star}$ & \pm 4.5 \\
Cord blood & 1.65 & 0.85 & 22.1 \\
& \pm 1.07 & \pm 0.39 & \pm 5.9 \\
Fetal/maternal & 4.4 & 2.8 & - \\
ratiot & \pm 1.9 & \pm 1.7 & - \\
\hline
\end{tabular}

Note: Each value represents the mean $\pm S D$ of blood samples taken during 16 deliveries.

^Significantly different $(P<0.001)$ from cord blood value according to Student's 't' test.

tCalculated using the mean maternal value for each delivery.

gradient in the term baby lies approximately between 12 (brainstem) and 25 (forebrain and cerebellum).

Neither plasma nor cell levels of ascorbic acid were altered during labour (Table II). Cord blood levels were much higher than those of maternal blood, the difference being more marked in plasma than in cells. Plasma urea levels did not differ between mother and fetus (Table II), in agreement with the finding that urea is not actively transported across the placenta (Battaglia et al., 1968).

Maternal plasma ascorbic acid in pregnancy was not significantly correlated with gestational age in the limited number of women examined. Women who were not pregnant had plasma levels 
significantly higher than those of women in the second and third trimesters (Table III) and also

\section{TABLE III}

Plasma ascorbic acid levels in women who were not pregnant and in women at different stages of pregnancy

\begin{tabular}{l|r|c|c}
\hline \multicolumn{1}{c|}{ Group } & No. & $\begin{array}{c}\text { Plasma ascorbic } \\
\text { acid }(\mathrm{mg} / 100 \mathrm{ml})\end{array}$ & Range \\
\hline Not pregnant & 13 & $0 \cdot 78 \pm 0 \cdot 36$ & $0 \cdot 26-1 \cdot 28$ \\
1st trimester & 8 & $0 \cdot 66 \pm 0 \cdot 42$ & $0 \cdot 22-1 \cdot 54$ \\
2nd trimester & 11 & $0 \cdot 50 \pm 0 \cdot 27^{\star}$ & $0 \cdot 07-0 \cdot 82$ \\
3rd trimester & 14 & $0 \cdot 51 \pm 0 \cdot 33^{\star}$ & $0 \cdot 22-1 \cdot 09$ \\
\hline
\end{tabular}

Note: Results are given as mean $\pm \mathrm{SD}$.

* Significantly different $(P<0.05)$ from the group that ivas not pregnant according to Student's ' $t$ ' test.

significantly $(P<0.02)$ greater than those of women at the onset of labour (Table II).

\section{Discussion}

This study has shown that in an unselected group of fetal and neonatal brains (1) ascorbic acid is a constituent of major quantitative importance, (2) levels of ascorbic acid are much higher than in adult brains, and (3) these levels fall with increasing length of gestation. For the reasons outlined in Methods, it seems unlikely that these general trends were affected by variations in vitamin $C$ intake, though such variations may have contributed to the relatively large scatter in forebrain concentrations at a given gestational age.

In large nutritional surveys it has been found that on a constant intake of vitamin C plasma concentrations may fall with increasing length of pregnancy (Teel et al., 1938; Martin et al., 1957). In this limited study, levels throughout pregnancy were generally lower than those of women who were not pregnant. Briggs and Briggs (1972) found that pregnancy was not associated with a fall in leucocyte vitamin C. However, women receiving oral contraceptives containing oestrogen had low ascorbic acid levels in both leucocytes and plasma (Briggs and Briggs, 1973). It has been suggested (Clemetson, 1968) that oestrogens increase ascorbic acid breakdown. Such an effect may be mediated, in blood at least, through oxidation of ascorbic acid by caeruloplasmin, levels of which rise during pregnancy and in women on oral contraceptives (Tovey and Lathe, 1968). It has been reported that the redox state of plasma ascorbic acid varies during the menstrual cycle (Kofoed et al., 1965). In mid-cycle, when oestrogen secretion is at its peak, ascorbic acid is present in a high proportion as its oxidized form. In summary, oestrogens may increase ascorbic acid oxidation and catabolism causing a rise in minimum requirement in pregnancy in addition to the demands of the growing fetus.

The minimum daily requirement for vitamin $C$ is a matter of continuing controversy (Krebs, 1953; Goldsmith, 1961; Yew, 1973), though it is agreed that the requirement is likely to rise during pregnancy. A mean plasma ascorbic acid level in late pregnancy of 0.4 to $0.5 \mathrm{mg} / 100 \mathrm{ml}$ (Tables II and III) probably indicates a daily intake of 40 to 60 mg (Martin et al., 1957; Goldsmith, 1961) at which tissues may not be completely saturated (Burch, 1961; Knox and Goswami, 1961). However, during vitamin $\mathrm{C}$ deficiency plasma levels may fall conspicuously before depletion of leucocytes (Lowry, 1952), so that a possible tissue deficit needs to be investigated more directly by examination of leucocyte levels in a similar group of pregnant women.

The present study confirms (Teel et al., 1938; Snelling and Jackson, 1939) that at term a marked transplacental gradient of ascorbic acid exists in favour of the fetus. The results suggest that this gradient is not influenced by labour. It is possible that the placenta may actively transport ascorbic acid by a mechanism similar to that which exists for amino acids (Dancis et al., 1968; Longo, Yuen, and Gusseck, 1973). Further, the brain may take up ascorbic acid from the blood by an energydependent process (Sharma, Johnstone, and Quastel, 1963). Whatever the mechanisms involved, it seems that the fetal brain at term concentrates ascorbic acid up to 100 -fold from maternal plasma. This agrees with autoradiographical studies on the pregnant mouse (Hammarstrom, 1967), and perhaps implies an important function for ascorbic acid in brain development.

The function of ascorbic acid in the nervous system is largely unknown. Scurvy in guinea-pigs is associated with conspicuous histological changes in sympathetic and sensory ganglion neurons (Weatherford, 1961; Sulkin, Sulkin, and Nushan, 1973) as well as alterations in brain amino acids (Enwonwu, 1973), but it is not clear to what extent these changes are a direct result of loss of neuronal vitamin C. Two major roles for ascorbic acid in adult brain metabolism have been suggested. First, it may exert control over catecholamine metabolism (Izquierdo, Jofré, and Acevedo, 1968; Stone and Townsley, 1973), particularly as a cofactor of dopamine- $\beta$-hydroxylase (Kaufman and Friedman, 
1965). Secondly, ascorbic acid at physiological concentrations inhibits brain $\mathrm{Na}^{+}-\mathrm{K}^{+}$-activated ATPase (Inagaki, 1970; Boxall and Phizackerley, 1973; Frey, Pitts, and Askari, 1973) and hence may have a regulatory action on the sodium pump. However, neither of these hypothetical functions would be expected to be as important in the immature as in the mature brain.

A further possibility, for which there is some indirect evidence (Rinaldi, 1960; Edgar, 1970), is that ascorbic acid and its oxidized form are regulators of cell division. Forebrain neuroblast multiplication is thought to occur mainly in the period 10 to 18 weeks' gestational age (Dobbing and Sands, 1970, 1973) at a time when ascorbic acid concentrations were found to be high. The possible involvement of ascorbic acid in neuronal division should be examined.

This work was supported by grants to Dr. John Dobbing from the Medical Research Council and the National Fund for Research into Crippling Diseases. We gratefully acknowledge the help of Miss Helen Furness, Miss Jean Sands, Drs. Caroline Day and M. Gartside, and the nursing staff from the Central Delivery Unit, St. Mary's Hospital.

\section{REFERENCES}

Adlard, B. P. F., De Souza, S. W., and Moon, S. (1973). The effect of age, growth retardation and asphyxia on ascorbic acid concentrations in developing brain. Fournal of Neurochemistry, 21, 877.

Allison, J. H., and Stewart, M. A. (1973). Myo-inositol and ascorbic acid in developing rat brain. Fournal of Neurochemistry, 20, 1785.

Baker, H., and Frank, O. (1968). Clinical Vitaminology, p. 153. Interscience, New York and London.

Battaglia, F. C., Behrman, R. E., Meschia, G., Seeds, A. E., and Bruns, P. D. (1968). Clearance of inert molecules, $\mathrm{Na}$, and $\mathrm{Cl}$ ions across the primate placenta. American fournal of Obstetrics and Gynecology, 102, 1135.

Boxall, R. R., and Phizackerley, P. J. R. (1973). Mechanism of the inhibition by ascorbate of the sodium-plus-potassium ionstimulated adenosine triphosphatase in rat brain. Biochemical Society Transactions, 1, 129.

Briggs, M., and Briggs, $M$. (1972). Vitamin $C$ requirements and oral contraceptives. Nature (London), 238, 277.

Briggs, M., and Briggs, M. (1973). Vitamin C and colds. Lancet, 1,998 .

Burch, H. B. (1961). Methods for detecting and evaluating ascorbic acid deficiency in man and animals. Annals of the New York Academy of Sciences, 92, 268.

Clemetson, C. A. B. (1968). Caeruloplasmin and green plasma. Lancet, 2, 1037.

Dancis, J., Money, W. L., Springer, D., and Levitz, M. (1968). Transport of amino acids by placenta. American fournal of Obstetrics and Gynecology, 101, 820.

Dobbing, J., and Sands, J. (1970). Timing of neuroblast multiplication in developing human brain. Nature (London), 226, 639.

Dobbing, J., and Sands, J. (1973). Quantitative growth and development of human brain. Archives of Disease in Childhood, 48, 757 .

Edgar, J. A. (1970). Dehydroascorbic acid and cell division. Nature (London), 227, 24.

Enwonwu, C. O. (1973). Alterations in ninhydrin-positive substances and cytoplasmic protein synthesis in the brains of ascorbic acid-deficient guinea pigs. fournal of Neurochemistry, 21, 69.
Evelyn, K. A., Malloy, H. T., and Rosen, C. (1938). The determination of ascorbic acid in urine with the photoelectric colorimeter. Fournal of Biological Chemistry, 126, 645.

Fawcett, J. K., and Scott, J. E. (1960). A rapid and precise method for the determination of urea. Fournal of Clinical Pathology, 13, 156.

Frey, M., Pitts, B. J. R., and Askari, A. (1973). Vitamin C-effects on the $\mathrm{Na}^{+}, \mathrm{K}^{+}$-adenosine triphosphate phosphohydrolase complexes of several tissues. Biochemical Pharmacology, 22, 9.

Goldsmith, G. A. (1961). Human requirements for vitamin C and its use in clinical medicine. Annals of the New York Academy of Sciences, 92, 230.

Hammarstrom, L. (1967). Autoradiographic studies on the distribution of $\mathrm{C}^{14}$-labelled ascorbic acid and dehydroascorbic acid. Acta Physiologica Scandinavica, 70, Suppl. 289, 3.

Hughes, R. E., Hurley, R. J., and Jones, P. R. (1971). The retention of ascorbic acid by guinea-pig tissues. British fournal of Nutrition, 26, 433.

Inagaki, C. (1970). Inhibition of $\mathrm{Mg}$ - and $\mathrm{Mg}, \mathrm{Na}, \mathrm{K}$-activated adenosine triphosphatase activity by $\mathrm{L}$-ascorbic acid and L-cysteine. Fapanese Fournal of Pharmacology, 20, 52.

Izquierdo, J. A., Jofré, I. J., and Acevedo, C. (1968). The effect of ascorbic acid on the cerebral and adrenal catecholamine content in the male rat. Fournal of Pharmacy and Pharmacology, 20, 210.

Kaufman, S., and Friedman, S. (1965). Dopamine- $\beta$-hydroxylase. Pharmacological Reviews, 17, 71.

Knox, W. E., and Goswami, M. N. D. (1961). Ascorbic acid in man and animals. Advances in Clinical Chemistry, 4, 121.

Kofoed, J. A., Blumenkrantz, N., Houssay, A. B., and Yamauchi, E. Y. (1965). Cervical mucus and serum ascorbic acid and dehydroascorbic acid concentrations during the menstrual cycle. American fournal of Obstetrics and Gynecology, 91, 95.

Krebs, H. A. (1953). The Sheffield experiment on the vitamin C requirement of human adults. Proceedings of the Nutrition Society, 12, 237.

Longo, L. D., Yuen, P., and Gusseck, D. J. (1973). Anaerobic, glycogen-dependent transport of amino acids by the placenta. Nature (London), 243, 531.

Lowry, O. H. (1952). Biochemical evidence of nutritional status. Physiological Reviews, 32, 431.

Lowry, O. H., Rosebrough, N. J., Farr, A. L., and Randall, R. J. (1951). Protein measurement with the Folin phenol reagent. Fournal of Biological Chemistry, 193, 265.

Martin, M. P., Bridgforth, E., McGanity, W. J., and Darby, W. J. (1957). The Vanderbilt cooperative study of maternal and infant nutrition X. Ascorbic acid. Fournal of Nutrition, 62 , 201.

Rinaldi, L. M. (1960). Growth and ascorbic acid content of the chick embryo. Fournal of Embryology and Experimental Morphology, 8, 527.

Roe, J. H., and Kuether, C. A. (1943). The determination of ascorbic acid in whole blood and urine through the 2,4dinitrophenylhydrazine derivative of dehydroascorbic acid. Fournal of Biological Chemistry, 147, 399.

Sharma, S. K., Johnstone, R. M., and Quastel, J. H. (1963). Active transport of ascorbic acid in adrenal cortex and brain cortex in vitro and the effects of ACTH and steroids. Canadian fournal of Biochemistry and Physiology, 41, 597.

Snelling, C. E., and Jackson, S. H. (1939). Blood studies of vitamin $\mathrm{C}$ during pregnancy, birth, and early infancy. Fournal of Pediatrics, 14, 447.

Stone, K. J., and Townsley, B. H. (1973). The effect of L-ascorbate on catecholamine biosynthesis. Biochemical fournal, 131, 611 .

Sulkin, D. F., Sulkin, N. M., and Nushan, H. (1973). Fine structure of sensory ganglia during experimental scurvy. Acta Neuropathologica, 23, 141.

Teel, H. M., Burke, B. S., and Draper, R. (1938). Vitamin C in human pregnancy and lactation. I. Studies during pregnancy. American fournal of Diseases of Children, 56, 1004.

Tovey, L. A. D., and Lathe, G. H. (1968). Caeruloplasmin and green plasma in women taking oral contraceptives, in pregnant women, and in patients with rheumatoid arthritis. Lancet, 2, 596.

Weatherford, T. (1961). Morphological and histochemical studies on the autonomic ganglia of scorbutic guinea pigs. Fournal of Neuropathology and Experimental Neurology, 20, 440. 
Yavorsky, M., Almaden, P., and King, C. G. (1934). The vitamin C content of human tissues. Fournal of Biological Chemistry, 106, 525.

Yew, M. L. S. (1973). 'Recommended daily allowances' for vitamin C. Proceedings of the National Academy of Sciences, U.S.A., 70, 969.
Correspondence to Dr. B. P. F. Adlard, Department of Child Health, University of Manchester, Clinical Sciences Building, York Place, Manchester M13 0JJ.

The following articles will appear in future issues of this journal:

Review article: Onset of respiration at birth. M. J. Purves.

Brain maturation and damage in infants dying from chronic pulmonary insufficiency in postneonatal period. J. F. Smith, E. O. R. Reynolds, and A. Taghizadeh.

Accidental head injury in childhood. D. L. Jamison and H. H. Kaye.

Effect of ascorbic acid on urinary hydroxyproline of children receiving corticosteroids. D. Liakakos, D. G. Ikkos, $P$. Vlachos, $K$. Ntalles, and C. Coulouris.

Iron status of preterm low birthweight infants and their response to oral iron. B. Brozović, W. L. Burland, $K$. Simpson, and J. Lord.

Cord haemoglobin in low birthweight infants. D. Burman and A. F. Morris.

Hydrocephalus related to pulsion diverticulum of lateral ventricle. M. Mott and B. Cummins.

Thyroxine levels in normal newborn infants. $R$. H. Davies, K. Lawton, and D. Waring. 